\title{
Canadian Cardiovascular Society Grading Scale Class IV
}

National Cancer Institute

\section{Source}

National Cancer Institute. Canadian Cardiovascular Society Grading Scale Class IV. NCI Thesaurus. Code C77268.

A grading of angina characterized by an inability to perform any physical activity without discomfort; anginal symptoms may be present at rest. 